\title{
Metabolic responses to hypoxia of Lycenchelys verrillii (wolf eelpout) and Glyptocephalus cynoglossus (witch flounder): sedentary bottom fishes of the Hatteras/Virginia Middle Slope
}

\author{
Mary L. Moser ${ }^{1, *}$, Steve W. Ross ${ }^{2}$, Kenneth J. Sulak ${ }^{3}$ \\ ${ }^{1}$ Center for Marine Science Research, 7205 Wrightsville Avenue, Wilmington, North Carolina 28403, USA \\ ${ }^{2}$ North Carolina National Estuarine Research Reserve, 7205 Wrightsville Avenue, Wilmington, North Carolina 28403, USA \\ ${ }^{3}$ Florida Caribbean Science Center, Biological Resources Division, United States Geological Survey, 7920 NW 71 st Street, \\ Gainesville, Florida 32653, USA
}

\begin{abstract}
We collected wolf eelpouts Lycenchelys verrillii and witch flounder Glyptocephalus cynoglossus from Hatteras (North Carolina, USA) and Virginia (USA) Middle Slope sites using a submersible, and made shipboard measurements of their respiration rates and survival in hypoxic $(<10 \%$ $\mathrm{O}_{2}$ saturation) and anoxic conditions. Both species from the Hatteras site reduced their respiration rates as ambient oxygen decreased, but eelpouts from the Virginia site maintained a constant respiration rate until oxygen saturation dropped below $20 \%$. Moreover, eelpouts from the Hatteras site were significantly more tolerant of hypoxic conditions than fish from the Virginia site and survived anoxia for short periods. These results and our submersible observations of fish behavior support the hypothesis that the Hatteras Middle Slope fauna is exposed to short-term hypoxia events
\end{abstract}

KEY WORDS: Deep sea fishes - Continental slope - Respiration - Anoxia Zoarcidae - Pleuronectidae

\section{INTRODUCTION}

An anomalous benthic fauna occurs on the middle continental slope off Cape Hatteras, North Carolina, USA (HMS), $35^{\circ} 30^{\prime} \mathrm{N}, 74^{\circ} 50^{\prime} \mathrm{W}$ (Blake \& Diaz 1994, Hecker 1994, Sulak \& Ross 1996). The invertebrate macro- and megafauna exhibit uneven species composition and high abundance in this region (Schaff et al. 1992, Blake \& Hilbig 1994, Hecker 1994). The benthic fish community is dominated by 4 sedentary species which occur in large numbers but exhibit reduced sizes when compared to those found on the Virginia Middle Slope (VMS), USA, only $150 \mathrm{~km}$ to the north (Sulak \& Ross 1996). Moreover, active, benthopelagic species that are common along the continental slope of the eastern United States are conspicuously absent at the HMS site. Sulak \& Ross (1996) hypothesized that these characteristics of the HMS benthic fish fauna may re-

•E-mail: moserm@uncwil.edu flect chronic or episodic reductions in near-bottom dissolved oxygen concentration.

We documented metabolic responses of the 2 dominant HMS fish species, wolf eelpout Lycenchelys verrillii and witch flounder Glyptocephalus cynoglossus, during decreasing oxygen conditions. In addition, we tested the hypoxia tolerance of fish collected at both the HMS and VMS sites. These deep-sea teleosts are both extremely hardy and have no gas bladder, making it possible to transport submersible-caught specimens to the surface unharmed and to conduct shipboard experiments on them. We relate these shipboard measurements to submersible observations of fish behavior in situ.

\section{METHODS}

All experiments were conducted from 25 June to 2 July 1992 aboard the RV 'Edwin Link'. Wolf eelpouts 


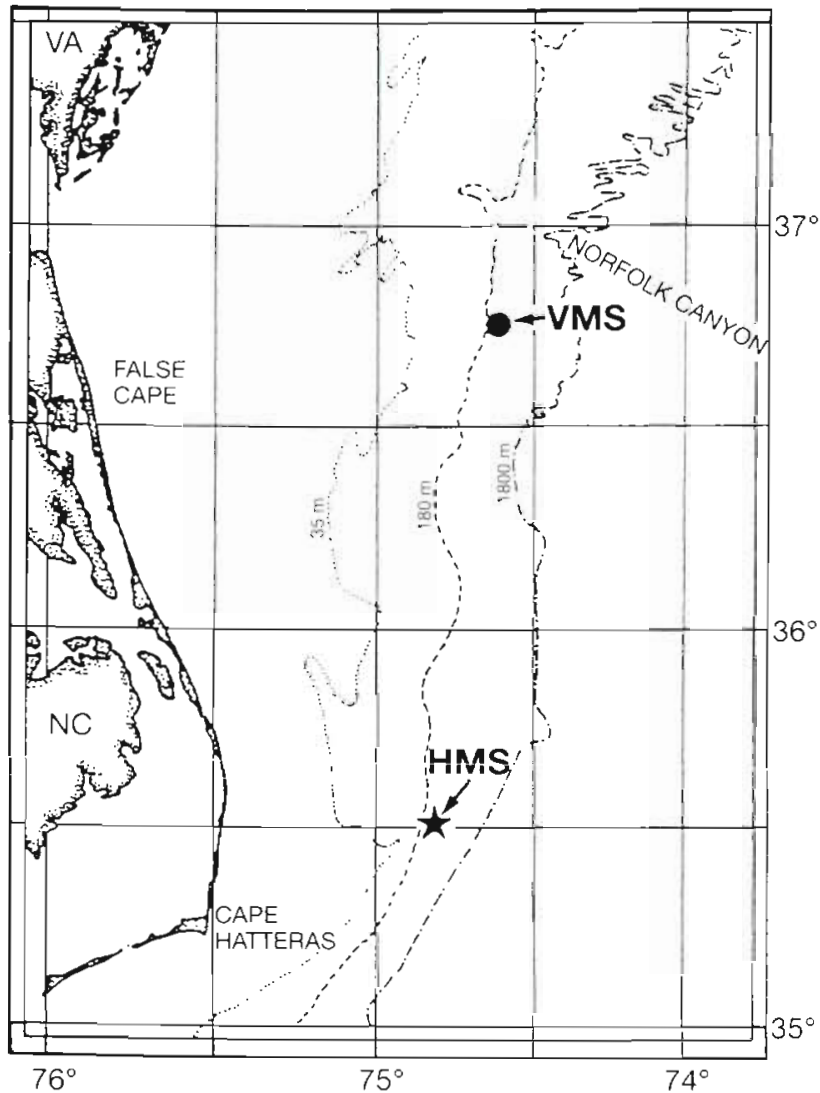

Fig. 1 Fish collection sites on the Virginia upper middle slope (VMS) and Hatteras upper middle slope (HMS)

and witch flounder were collected on the Hatteras Upper Middle Slope in the area $35^{\circ} 29-30^{\prime} \mathrm{N}, 74^{\circ}$ $47-48^{\prime} \mathrm{W}$, and on the Virginia Upper Middle Slope in the area $36^{\circ} 45-46^{\prime} \mathrm{N}, 74^{\circ} 37-38^{\prime} \mathrm{W}$ (Fig 1) All fish were collected in depths ranging from 530 to $840 \mathrm{~m}$ using a suction sampler operated from the DSRV 'Johnson-Sea-Link'. Bottom temperatures at the collection sites ranged from 4.5 to $5.2^{\circ} \mathrm{C}$ and oxygen saturation ranged from 65 to $80 \%$. Fish were drawn into plexiglass containers at depth and, immediately upon surfacing, were transferred from ambient seawater to 761 aquaria located in a darkened coldroom $\left(6^{\circ} \mathrm{C}\right)$. All fish were acclimated in the coldroom for at least $24 \mathrm{~h}$ before experimentation and were not fed. No fish mortality occurred in the aquaria throughout the $8 \mathrm{~d}$ cruise.

We measured oxygen consumption by using two $245 \mathrm{ml}$ static respiration chambers that were each fitted with a polarographic oxygen. electrode. For each trial, 1 randomly selected fish was gently coaxed into each of the 2 chambers. The chambers were placed in a cold water bath to maintain temperature at $6.0^{\circ} \mathrm{C}$ $\left( \pm 0.3^{\circ} \mathrm{C}\right)$ and were positioned over a white surface. Red-filtered lighting in the cold room made the silhou- ette of each fish visible from above for observations of ventilation rate, but the sides of the water bath were shielded to minimize fish disturbance during counts of opercular strokes (Heath 1972).

Oxygen concentration ( $\mathrm{mg} \mathrm{l}^{-1}$ ) and temperature $\left({ }^{\circ} \mathrm{C}\right)$ in the chambers were recorded continuously at $10 \mathrm{~s}$ intervals with a laptop computer. At 15 min intervals the ventilation rate (strokes $\mathrm{min}^{-1}$ ) of each fish was determined from the mean of 3 counts of opercular strokes, and the respiration chambers were then rocked to promote adequate mixing. Both species were quiescent in the chambers, even during mixing. Only maximum oxygen concentrations recorded after each mixing were used for analysis. Oxygen in the chambers was depleted by the fish at a rate of approximately $1 \mathrm{mg} \mathrm{O} \mathrm{O}_{2} \mathrm{l}^{-1} \mathrm{~h}^{-1}\left(10 \% \mathrm{O}_{2}\right.$ saturation $\left.\mathrm{h}^{-1}\right)$ and average experiment duration was $8 \mathrm{~h}$.

Respiration measurements were made around-theclock and were terminated when the fish no longer operculated and were presumed dead. The lower lethal oxygen saturation was defined as the oxygen saturation in the chambers when fish died. Each specimen was frozen for later determination of wet weight (to the nearest $0.01 \mathrm{~g}$ ). The chambers were then flushed and oxygen measurements were taken in chambers without fish to document background respiration (Cech 1990)

We monitored survival of HMS wolf eelpouts during slower rates of oxygen depletion (approximately $0.3 \mathrm{mg} \mathrm{O}_{2} \mathrm{l}^{-1} \mathrm{~h}^{-1}$ ) in a closed $3.9 \mathrm{l}$ chamber equipped with a polarographic oxygen electrode. In the first and second trials, 6 and 8 fish, respectively, were placed in the chamber, and oxygen saturation was monitored at $1 \mathrm{~h}$ intervals. Mean lower lethal oxygen saturation, percent survival when oxygen dropped below $10 \%$ saturation (hypoxia), and percent survival when all axygen had been depleted (anoxia) were recorded In the first trial the hypoxic treatment lasted $8.2 \mathrm{~h}$ and in the second trial it lasted $6.5 \mathrm{~h}$. Experiments were terminated when $50 \%$ of the fish no longer operculated and were presumed dead. All fish were frozen for later measurement of wet weight.

Respiration and ventilation rates were determined for wolf eelpouts at both the HMS $(n=8)$ and VMS $(\mathrm{n}=6)$ sites, but witch flounder from only the HMS site $(n=8)$ were used (this species was too difficult to catch at the VMS site). Oxygen measurements were erratic in both control and experimental chambers during the first hour of each experiment, so measurements taken during this period were not used in the analysis. Background respiration after this period was negligible. Mean weight-independent respiration rates (mg $\mathrm{O}_{2} \mathrm{~g}^{-0.7} \mathrm{~h}^{-1}$ ) and ventilation rates (strokes $\mathrm{min}^{-1}$ ) in oxygen saturations from 70 to $0 \%$ (at intervals of $5 \%$ saturation) were calculated for each fish. Due to the lack of 
fish activity in the chambers, we assumed a mass exponent of 0.7 for fish at standard metabolism (Cech 1990). A mass exponent of 0.7 has also been reported for a blenny (Innes \& Wells 1985) and a goby (Petersen \& Petersen 1990), which are both quiescent during respiration measurements.

We tested for effects of oxygen saturation, weight, chamber and collection site on respiration rate using analysis of covariance (Zar 1984). Mean lower lethal oxygen saturation (oxygen saturation when fish ceased gill ventilation), percent survival in hypoxic and anoxic water, and the number of minutes fish survived anoxia were determined for fish in the respiration chambers. Comparisons of lower lethal oxygen saturation between size classes and collection sites were made using the Wilcoxon Rank Sum test (Zar 1984).

\section{RESULTS}

Both species collected at the HMS site exhibited similar responses to decreasing oxygen saturation (Fig. 2). Respiration rates were positively correlated $(p<0.05$, ANCOVA) with oxygen saturation (Fig. 2) and there was no significant effect ( $p>0.05$. ANCOVA) of fish weight on respiration rates for either species. Mean respiration rates for wolf eelpouts and witch flounder in oxygen saturation $>10 \%$ were 0.051 and 0.067 $\mathrm{mg} \mathrm{O}_{2} \mathrm{~g}^{-0.7} \mathrm{~h}^{-1}$, respectively. Ventilation rate was constant until oxygen saturation dropped below $15 \%$, and then it decreased sharply (Fig. 2). We did not measure stroke volume, but at low oxygen saturations we noted that gill ventilation was exaggerated, and that fish exhibited gulping movements which probably increased stroke volume. A similar compensatory increase in stroke volume has been documented in other species (Steffensen et al. 1982).

The relationship between oxygen saturation and respiration rates of wolf eelpouts from the 2 sites differed significantly $(\mathrm{p}<0.05$, ANCOVA). Fish from the VMS site maintained a constant rate of oxygen consumption (mean $=0.051 \mathrm{mg} \mathrm{O}_{2} \mathrm{~g}^{-0.7} \mathrm{~h}^{-1}$ ) until oxygen saturation neared $20 \%$ (Fig. 2). Respiration then suddenly dropped
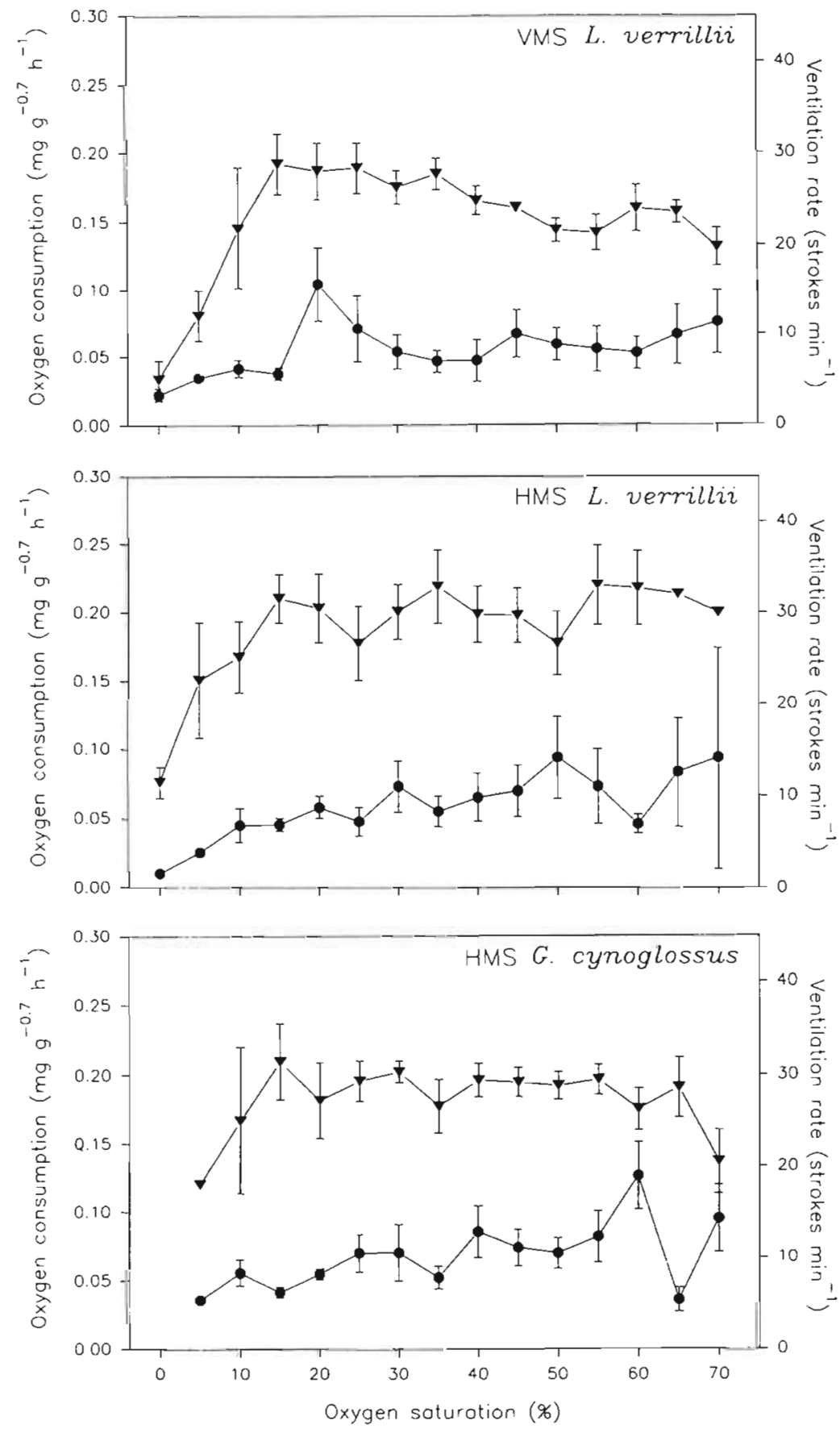

Fig. 2. Lycenchelys verrillii and Glyptocephalus cynoglossus. Mean respiration $(-)$ and ventilation ( $\nabla$ ) rates during decreasing ambient oxygen for wolf eelpouts collected at the VMS $(n=6)$ and HMS $(n=8)$ sites, and witch flounder collected at the HMS site ( $\mathrm{n}=8$ ). Bars represent standard errors of the mean to approximately half of the initial rate. Respiration rates of fish collected at the HMS site gradually decreased with decreasing oxygen availability, and did not exhibit the stepped response noted in VMS fish (Fig. 2)

In respiration chambers, wolf eelpouts from both sites survived hypoxia longer than witch flounder, and 
Table 1. Lycenchelys verrillii and Glyptocephalus cynoglossus. Tolerance of hypoxia and anoxia by wolf eelpouts and witch flounder collected from the Hatteras (HMS) and Virgina (VMS) Middle Slope. Mean lower lethal oxygen saturation (\%), and \% and duration (min) of survival in hypoxia $\left(<10 \% \mathrm{O}_{2}\right.$ saturation) and in anoxia are given for each collection site. SE shown in parentheses

\begin{tabular}{|c|c|c|c|c|c|c|c|}
\hline & \multirow[t]{2}{*}{$\mathrm{n}$} & \multirow{2}{*}{$\begin{array}{l}\text { Mean weight } \\
\text { (g wet wt) }\end{array}$} & \multirow{2}{*}{$\begin{array}{c}\text { Lower lethal } \mathrm{O}_{2} \\
\text { saturation }(\%)\end{array}$} & \multicolumn{2}{|c|}{ Survival in hypoxia } & \multicolumn{2}{|c|}{ Survival in anoxia } \\
\hline & & & & $\%$ & Duration (min) & $\%$ & Duration (min) \\
\hline \multicolumn{8}{|c|}{$L$ verrillii } \\
\hline VMS & 6 & $6.40( \pm 0.67)$ & $7.9( \pm 3.3)$ & 50 & $52( \pm 34)$ & 17 & $5( \pm 3)$ \\
\hline HMS & 8 & $6.85( \pm 0.81)$ & $2.0( \pm 3.3\}$ & 75 & $130( \pm 41)$ & 50 & $36( \pm 16)$ \\
\hline \multicolumn{8}{|c|}{ G. cynoglossus } \\
\hline HMS & 8 & $5.33( \pm 0.55)$ & $15.9( \pm 5.9)$ & 25 & $8( \pm 7)$ & 0 & 0 \\
\hline
\end{tabular}

wolf eelpouts from the HMS site survived longer than those from the VMS site (Table 1). The lower lethal oxygen saturation for wolf eelpouts was significantly lower $(p<0.05)$ than that of witch flounder, and the lower lethal oxygen saturation for HMS wolf eelpouts was significantly lower $(p<0.05$ ) than that of VMS wolf eelpouts (Table 1). Fish size had no significant effect on the lower lethal oxygen saturation ( $p>0.05$ ). Half of the wolf eelpouts from the HMS site survived anoxia, with survival ranging from 30 to $105 \mathrm{~min}$ in $0 \%$ saturation (Table 1). Only 1 VMS eelpout, and no witch flounder survived anoxia (Table 1).

Survival of wolf eelpouts from the HMS site that we subjected to slower rates of oxygen depletion also indicated that these fish were extremely resistant to hypoxic conditions. In both trials, all fish survived at least $4 \mathrm{~h}$ in $<10 \%$ oxygen saturation (mean duration \pm $\mathrm{SE}=6.2 \pm 0.8 \mathrm{~h}$ ) and $50 \%$ of the fish survived anoxic conditions. In the first trial, mean lower lethal oxygen saturation was $2.3 \%(\mathrm{SE}= \pm 1.1 \%, \mathrm{n}=6)$. Lower lethal oxygen saturation in the second trial was not computed due to missing data.

\section{DISCUSSION}

We attribute the low respiration rates of wolf eelpouts and witch flounder in oxygenated water to the combined effects of low environmental temperature, depth of occurrence, and fish lifestyle. Torres et al. (1979) found that metabolism of midwater fishes is negatively correlated with minimum depth of occurrence (depth below which $90 \%$ of the population lives). By modeling this relationship, they found that the low respiration rates of deep-living species cannot be attributed solely to ambient temperature. Cowles \& Childress (1995) attributed the low respiration rates of anglerfish Melanocetus johnsoni to the sluggish habits of this bathypelagic sit-and-wait predator. Respiration rates of the wolf eelpouts and witch flounder we measured were slightly lower than those predicted by the Torres et al. (1979) model, and may reflect the sedentary nature of the wolf eelpouts and witch flounder.

The metabolic strategies of the 2 most common HMS species indicated that short-term hypoxic events are likely on the HMS. Both wolf eelpouts and witch flounder from the HMS site exhibited continuous decreases in respiration as oxygen saturation decreased. This response to hypoxia is similar to that of the eelpout Zoarces viviparus, which inhabits a highly unpredictable oxygen environment where hypoxic events occur (Fischer et al. 1992). Fischer et al. (1992) suggested that eelpouts start to reduce respiration and activity at an early phase of oxygen depletion to extend their survival time in hypoxic conditions. In contrast, a zoarcid which occurs in chronic hypoxia, Melanostigma pammelas, maintains a constant respiration rate during oxygen deprivation until the lowest levels they encounter in the oxygen minimum layer are reached (Belman \& Gordon 1979).

Wolf eelpouts from the HMS site exhibited considerable anaerobic capabilities, which also supports the hypothesis that short-term hypoxia occurs at this site. In contrast, organisms adapted to chronic hypoxia do not exhibit anaerobic metabolism because they have no opportunity to repay their oxygen debt (Childress 1975, Belman \& Gordon 1979, Vetter et al. 1994). As in our observations of the wolf eelpout, Fischer et al. (1992) found that Zoarces viviparus survived shortterm anoxia and that gill ventilation ceased after $20 \mathrm{~min}$ in $0 \%$ saturation. However, they were able to revive the apparently dead fish after $60 \mathrm{~min}$ anoxia treatments. We did not attempt to revive the wolf eelpouts after gill ventilation stopped, but it is possible that they were still alive when we terminated the experiments. In this case, our estimates of their anaerobic abilities were probably conservative.

Wolf eelpouts exhibited significant site-specific differences in their response to hypoxia and in their behavior in situ. Respiration of fish from the VMS site was independent of ambient oxygen to a critical oxygen saturation of $20 \%$, and their lower lethal $\mathrm{O}_{2}$ saturation was significantly higher than that of wolf 
eelpouts from the HMS site. During submersible transects we noted that both wolf eelpouts and witch flounder were more active at the VMS site than at the HMS site. In fact, collection of fish at the VMS site was more difficult because they actively avoided the suction sampler. Fish at the HMS site were easily collected and rarely swam away when approached or touched by the submersible. These behaviors may reflect a lower scope for activity at the HMS site due to oxygen limitation (Van den Thillart et al. 1994).

The differences in hypoxia tolerance that we found in wolf eelpouts from the HMS and VMS sites could reflect ontogenetic changes, physiological acclimatization, or microgeographical genetic differences in the 2 groups. Size-specific changes in anaerobic capacity and hypoxia tolerance have been documented in other species (Peterson \& Gilmore 1991, Vetter et al. 1994). We were not able to collect enough large individuals to test for ontogenetic changes; however, within the size range we tested ( 4 to $11 \mathrm{~g}$ ) there was no evidence that hypoxia tolerance was related to size. We propose that periodic hypoxia on the HMS has caused site-specific physiological acclimatization at either the individual or population level. Wolf eelpouts have no mechanism for wide dispersal, having small numbers of benthic, precocial offspring (Anderson 1984). If HMS hypoxic events have persisted for a long time in relation to the generation length of wolf eelpouts, genetic changes could have resulted (Slobodkin \& Rapoport 1974). Microgeographical (20 to $40 \mathrm{~km}$ ) genetic differentiation has been documented in the eelpout Zoarces viviparus (Frydenberg et al. 1973), and it seems probable that genetically-based physiological differences could evolve in Lycenchelys verrillii over similar distances on the continental slope of the United States.

Acknowledgements. Special thanks to $M$. Trudeau for his help in running experiments. Thanks also to the crew of the 'Johnson-Sea-Link' for their help in fish collection, and to the crew of the 'Edwin Link' for accomodating the shipboard experiments. This work was supported in part by the National Undersea Research Center at the University of North Carolina, Wilmington, under grant \#NA88AA-D-UR0004, the North Carolina National Estuarine Research Reserve, and a research grant (OGP0003164) from the Canadian Natural Sciences and Engineering Research Council.

\section{LITERATURE CITED}

Anderson ME (1984) Zoarcidae: development and relationships. In: Moser HG, Richards WJ, Cohen DM, Fahay MP, Kendall AW Jr, Richardson SL (eds) Ontogeny and systematics of fishes. American Society of Ichthyologists and Herpetologists, Spec Publ 1, Allen Press, Lawrence, KS

Belman BW, Gordon MS (1979) Comparative studies on the metabolism of shallow-water and deep-sea marine fishes. $\checkmark$. Effects of temperature and hydrostatic pressure on oxy- gen consumption in the mesopelagic zoarcid Melanostigma pammelas. Mar Biol 50:275-281

Blake JA, Diaz RJ (1994) Input, accumulation and cycling of materals on the continental slope off Cape Hatteras: an introduction. Deep Sea Res II 41:707-710

Blake JA, Hilbig B (1994) Dense infaunal assemblages on the continental slope of Cape Hatteras, North Carolina. Deep Sea Res II 41: 875-900

Cech JJ Jr (1990) Respirometry. In: Schreck CB, Moyle PB (eds) Methods for fish biology. American Fisheries Society. Bethesda, MD

Childress JJ (1975) The respiratory rates of midwater crustaceans as a function of depth of occurrence and relation to the oxygen minimum layer off southern California. Comp Biochem Physiol 50A:787-799

Cowles DL, Childress JJ (1995) Aerobic metabolism of the anglerfish Melanocetus johnsoni, a deep-pelagic marine sit-and-wait predator. Deep Sea Res I 42:1631-1638

Fischer P, Rademacher K, Kils U (1992) In situ investigations on the respiration and behaviour of the eelpout Zoarces viviparus under short-term hypoxia. Mar Ecol Prog Ser 88: $181-184$

Frydenberg O, Gyldenholm AO, Hjorth JP, Simonsen $V$ (1973) Genetics of Zoarces populations IIl. Geographic variations in the esterase polymorphism EstIII. Hereditas 73:233-238

Heath AG (1972) A critical comparison of methods for measuring fish respiratory movements. Water Res $6: 1-7$

Hecker B (1994) Unusual megafaunal assemblages on the continental slope off Cape Hatteras. Deep Sea Res Il 41:809-834

Innes AJ, Wells RMG (1985) Respiration and oxygen transport functions of the blood from an intertidal fish, Helcogramma medium (Tripterygiidae). Environ Biol Fish 14:213-226

Petersen JK, Petersen Gl (1990) Tolerance, behaviour and oxygen consumption in the sand goby, Pomatoschistus minutus (Pallus), exposed to hypoxia. J Fish Biol 37 921-933

Peterson MS, Gilmore RG (1991) Eco-physiology of juvenile snook Centropomus undecimalis (Bloch): life-history implications. Bull Mar Sci 48:46-57

Schaff $T$, Levin L, Blair N, DeMaster D, Pope R, Boehme S (1992) Spatial heterogeneity of benthos on the Carolina continental slope: large $(100 \mathrm{~km})$-scale variation. Mar Ecol Prog Ser 88:143-160

Slobodkin LB, Rapoport A (1974) An optimal strategy for evolution. Q Rev Biol 49:181-200

Steffensen JF, Lomholt JP, Johansen K (1982) Gill ventilation and $\mathrm{O}_{2}$ extraction during graded hypoxia in two ecologically distinct species of flatfish, the flounder (Platichthys flesus) and the plaice (Pleuronectes platessa). Environ Biol Fish 7:157-163

Sulak KJ, Ross SW (1996) Lilliputian bottom fish fauna of the Hatteras upper middle continental slope. J Fish Biol 49(A) $1-23$

Torres JJ, Belman BW, Childress JJ (1979) Oxygen consumption rates of midwater fishes as a function of depth of occurrence. Deep Sea Res 26A:185-197

Van den Thillart G, Dalla Via J, Vitali G, Cortesi P (1994) Influence of long-term hypoxia exposure on the energy metabolism of Solea solea. I. Critical $\mathrm{O}_{2}$ levels for aerobic and anaerobic metabolism. Mar Ecol Prog Ser 104:109-117

Vetter RD, Lynn EA, Garza M. Costa AS (1994) Depth zonation and metabolic adaptation in Dover sole, Microstomus pacificus, and other deep-living flatfishes: factors that affect the sole. Mar Biol 120:145-159

Zar JH (1984) Biostatistical analysis. Prentice Hall Inc, Englewood Cliffs, NJ 